03.4

\title{
Исследование межфазного натяжения на границе воды и раствора асфальтенов в толуоле
}

\author{
(C) Р.Р. Зиннатуллин, А.И. Искандаров, Л.А. Ковалева
}

Башкирский государственный университет, Уфа, Россия

E-mail: rasulz@yandex.ru

Поступило в Редакцию 5 апреля 2021 г.

В окончательной редакции 10 декабря 2021 г.

Принято к публикации 11 декабря 2021 г.

\begin{abstract}
Исследована динамика коэффициента межфазного натяжения на границе воды и модельных растворов асфальтенов различной концентрации в толуоле. Показано, что с течением времени происходит снижение межфазного натяжения, обусловленное адсорбцией асфальтеновых молекул на границе раздела фаз. С ростом концентрации асфальтенов в растворе снижение межфазного натяжения происходит интенсивнее. Представлены результаты исследования удлинения капли воды в растворе при воздействии электрического поля. Показано, что после образования адсорбционной пленки для растяжения капли необходимо прикладывать более высокую напряженность, а относительное удлинение нелинейно зависит от прикладываемого напряжения. Исследования проведены с использованием метода подвешенной капли.
\end{abstract}

Ключевые слова: коэффициент межфазного натяжения, асфальтены, адсорбционная пленка, удлинение капли.

DOI: 10.21883/PJTF.2022.05.52154.18807

Стабильность водонефтяных эмульсий напрямую связана с образованием адсорбционной пленки на границе раздела воды и нефти. Такие межфазные пленки возникают в результате необратимой адсорбции и агрегации молекул асфальтенов на границе раздела фаз $[1,2]$.

Образование адсорбционных пленок и стабильность нефтяных эмульсий создают особые трудности в процессах добычи, транспортировки и подготовки нефти, поэтому многие технологии нефтедобычи направлены на ослабление и разрушение подобных пленок.

Адсорбционные пленки характеризуются определенными физическими свойствами, которые обусловлены способностью молекул асфальтенов взаимодействовать друг с другом и образовывать структурированные адсорбционные слои. Наиболее значимыми из них являются межфазное натяжение на границе раздела фаз, упругость и вязкость адсорбционной пленки, а также время ее образования [3-5].

Для образования адсорбционных пленок необходимо определенное время, т.е. время установления адсорбционного равновесия. По мере адсорбции частиц свойства пленки будут меняться, и соответственно будут меняться свойства всей системы. Анализ экспериментов по исследованию адсорбции асфальтенов на границе раздела фаз различными методами показал, что процессы адсорбции и перегруппировки протекают более суток. Но тем не менее наиболее интенсивные процессы ограничиваются временем менее часа [6-9]. Цель настоящей работы — исследование динамики межфазного натяжения на границе воды и раствора асфальтенов в толуоле при различной концентрации асфальтенов, а также относительного удлинения капли с асфальтеновой оболочкой.
Для определения межфазного натяжения на границе воды и раствора асфальтенов в толуоле с течением времени использовался метод подвешенной капли [10]. Асфальтены были получены осаждением из нефти нгептаном и многократным растворением в толуоле для удаления молекул смол, связанных с агрегатами асфальтенов [11]. Модельные растворы различной концентрации были получены растворением извлеченных асфальтенов определенной массы в толуоле. Вода очищалась с использованием фильтрующего устройства Milli-Q. Межфазное натяжение на границе воды с чистым толуолом оставалось постоянным на уровне $36 \pm 1 \mathrm{mN} / \mathrm{m}$ в течение $10 \mathrm{~h}$. Все эксперименты проводились при $25^{\circ} \mathrm{C}$. Кроме свободного межфазного натяжения в работе определялось относительное удлинение подвешенной капли без пленки и после образования адсорбционной пленки под действием электрического поля.

Для исследования изменения формы капли была собрана экспериментальная установка (рис. 1). Капля воды выдувается в модельные растворы асфальтенов с различной массовой концентрацией в толуоле, и в течение $2 \mathrm{~h}$ проводится фотосъемка капли с помощью фотокамеры. Анализируется форма капель с течением времени согласно методике, предложенной в [11], и строятся зависимости межфазного натяжения от времени для различных концентраций асфальтенов в модельном растворе.

На рис. 2 показано изменение во времени межфазного натяжения на границе воды с раствором асфальтенов в толуоле при различных массовых концентрациях асфальтенов в растворе. Из рис. 2 видно, что со временем межфазное натяжение снижается, и чем выше концентрация асфальтенов в растворе, тем быстрее и 


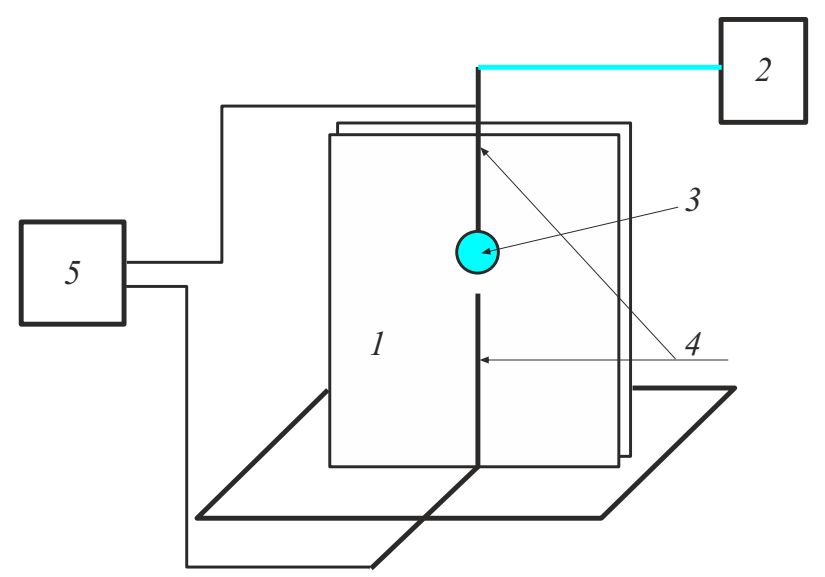

Рис. 1. Схема экспериментальной установки. 1 - вертикальная ячейка с модельным раствором, 2 - шприцевой насос, 3 - капля воды, 4 - электроды, 5 - генератор.

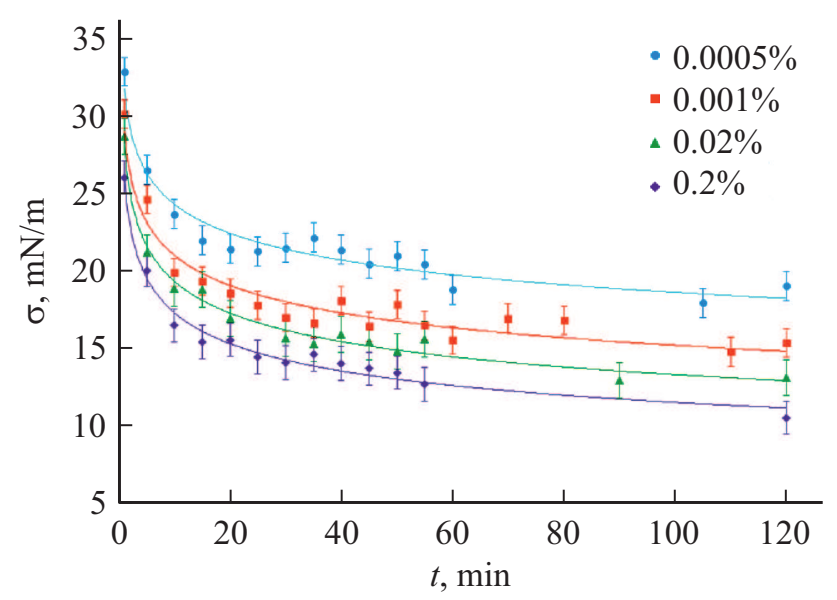

Рис. 2. Изменение во времени межфазного натяжения на границе воды с модельным раствором асфальтенов в толуоле при различных массовых концентрациях асфальтенов в растворе.

на бо́льшую величину снижается коэффициент межфазного натяжения. Процесс выдувания капли занимает до $1 \mathrm{~min}$, поэтому первые снимки были сделаны через 1 min после начала выдувания капли. Из рис. 2 видно, что в процессе выдувания капли происходит довольно интенсивная адсорбция молекул асфальтенов. Например, при концентрации асфальтенов в растворе, равной $0.2 \%$, коэффициент межфазного натяжения снижается с 36 до $26 \mathrm{mN} / \mathrm{m}$ за $1 \mathrm{~min}$.

Из представленных кривых видно также, что наиболее интенсивное снижение коэффициента межфазного натяжения происходит в начальные 20-30 min. Затем наблюдается менее интенсивное уменьшение межфазного натяжения. Аналогичные результаты были получены авторами при исследовании образования адсорбционной пленки на границе воды и нефти методом высокочастотной диэлектрической спектрометрии [9]. Поэтому при дальнейших исследованиях удлинения капель воды с адсорбционной пленкой при воздействии электрического поля мы ограничивались временем $20 \mathrm{~min}$.

Снижение межфазного натяжения со временем объясняется тем, что молекулы асфальтенов самопроизвольно ориентируются на поверхности раздела фаз. В результате уменьшается разность полярностей для соседних фаз, что по правилу Ребиндера приводит к снижению межфазного натяжения [12]. Согласно теории мономолекулярной адсорбции [12], каждый активный центр способен взаимодействовать только с одной молекулой адсорбата, в результате на поверхности может образоваться только один слой адсорбированных молекул. После образования монослоя, т. е. при достижении оптимальной концентрации асфальтенов на поверхности, значение межфазного натяжения не изменяется. Этим объясняется незначительное изменение межфазного натяжения через 20-30 min. Также, согласно теории Ленгмюра, процесс адсорбции находится в динамическом равновесии с процессом десорбции. Этим можно объяснить некоторые скачки значений межфазного натяжения в правой части кривых $\sigma(t)$.

На рис. 3 представлены зависимости удлинения капель воды от напряженности электрического поля с частотой $10 \mathrm{kHz}$ после выдержки в течение $20 \mathrm{~min}$ в растворе толуола с содержанием асфальтенов 0.1\%. Показано, что через $20 \mathrm{~min}$ для растяжения капли необходимо прикладывать электрическое поле более высокой напряженности, что объясняется образованием прочной адсорбционной пленки на поверхности воды из молекул асфальтенов. Ход кривой для капли с пленкой аналогичен типичным кривым растяжения эластичных материалов [13]. Относительное удлинение капли с адсорбционной пленкой нелинейно зависит от прикладываемого напряжения, выше значения 0.075 относительное удлинение в зависимости от напряженности приложенного поля меняется незначительно, в то время как для капли без оболочки эта кривая имеет линейный характер.

Таким образом, на основе результатов экспериментальных исследований было показано, что процесс ад-

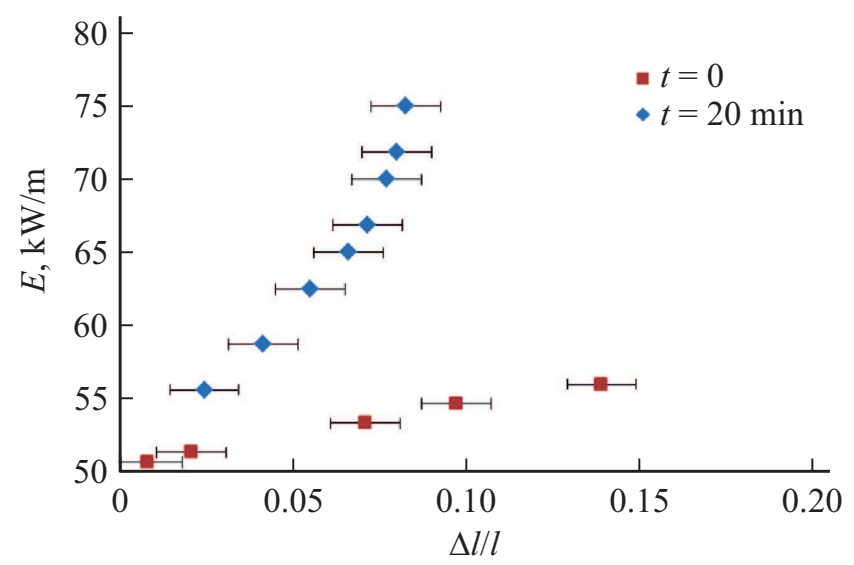

Рис. 3. Зависимости от напряженности электрического поля относительного удлинения капель воды с адсорбционной пленкой и без нее в толуоле. 
сорбции асфальтенов на поверхности воды происходит наиболее интенсивно в течение 20-30 min при всех исследуемых концентрациях асфальтенов в растворе. За этот период времени образуется устойчивая адсорбционная пленка, способная растягиваться подобно эластичным материалам при наложении силы. Полученные результаты могут быть использованы при математическом моделировании процессов фазоразделения водонефтяных эмульсий, в том числе в результате воздействия электромагнитного поля, а также будут полезны при выработке рекомендаций для разработки методов фазоразделения водонефтяных эмульсий с использованием физических полей. Например, воздействие на эмульсию электромагнитных полей приводит к ослаблению и разрыву адсорбционной оболочки. Если после этого капли не успевают коагулировать и коалесцировать, эмульсии возвращаются в исходное состояние. Поэтому в таких ситуациях необходимо ускорить эти процессы. По результатам проведенных исследований можно спрогнозировать времена релаксации эмульсионных систем в зависимости от содержания молекул асфальтенов и при необходимости рекомендовать дополнительные методы воздействия для ускорения процессов коагуляции. Другая рекомендация может быть дана при использовании электродегидраторов при обезвоживании нефти: в этом случае необходимо ограничивать значения напряженности электрического поля в зависимости от прочности бронирующих оболочек для предотвращения преждевременного разрыва оболочки и перехода эмульсии в более мелкодисперсное состояние.

\section{Финансирование работы}

Исследования выполнены за счет гранта Российского научного фонда (проект № 19-11-00298).

\section{Конфликт интересов}

Авторы заявляют, что у них нет конфликта интересов.

\section{Список литературы}

[1] Р.З. Сафиева, Физикохимия неббти (Химия, М., 1998).

[2] J.D. McLean, P.K. Kilpatrick, J. Coll. Interface Sci., 196 (1), 23 (1997). DOI: 10.1006/jcis.1997.5177

[3] E.M. Freer, T. Svitova, C.J. Radke, J. Petrol. Sci. Eng., 39 (1-2), 137 (2003). DOI:10.1016/S0920-4105(03)00045-7

[4] E.M. Freer, C.J. Radke, J. Adhesion, 80 (6), 481 (2004). DOI: $10.1080 / 00218460490477143$

[5] N. Aske, R. Orr, J. Sjöblom, H. Kallevik, G. Øye, J. Dispersion Sci. Technol., 25 (3), 263 (2004). DOI: $10.1081 /$ DIS-120037694

[6] F. Bauget, D. Langevin, R. Lenormand, J. Coll. Interface Sci., 239 (2), 501 (2001). DOI: 10.1006/jcis.2001.7566

[7] M. Jeribi, B. Almir-Assad, D. Langevin, I. Henaut, J.F. Argillier, J. Coll. Interface Sci., 256 (2), 268 (2002). DOI: $10.1006 /$ jcis. 2002.8660
[8] H.W. Yarranton, H. Alboudwarej, R. Jakher, Industr. Eng. Chem. Res., 39 (8), 2916 (2000). DOI: 10.1021/ie000073r

[9] Р.Р. Зиннатуллин, Ю.И. Фатхуллина, И.М. Камалтдинов, Теплофизика высоких температур, 50 (2), 316 (2012). [R.R. Zinnatullin, Yu.I. Fatkhullina, I.M. Kamaltdinov, High Temp., 50 (2), 298 (2012). DOI: 10.1134/S0018151X1202023X].

[10] F.K. Hansen, G. Rødsrud, J. Coll. Interface Sci., 141 (1), 1 (1991). DOI: 10.1016/0021-9797(91)90296-K

[11] O.P. Strausz, P. Peng, J. Murgich, Energy Fuels, 16 (4), 809 (2002). DOI: 10.1021/ef0002795

[12] Ю.Г. Фролов, Курс коллоидной химии. Поверхностные явления и дисперсные системы (Альянс, М., 2004).

[13] E.M. Arruda, M.C. Boyce, J. Mech. Phys. Solids, 41 (2), 389 (1993). DOI: 10.1016/0022-5096(93)90013-6 